\title{
THE EFFECT OF CASEIN PHOSPHOPEPTIDE-AMORPHOUS CALCIUM PHOSPHATE-PROPOLIS CHEWING GUM ON CALCIUM AND PHOSPHATE ION LEVELS IN CARIES-FREE SUBJECT'S SALIVA AND STREPTOCOCCUS MUTANS BIOFILM FORMATION
}

\author{
SRI ANGKY SOEKANTO ${ }^{1 *}$, GADIA CANAPARIMITA GHRENA DUHITA ${ }^{1}$, ENDANG WINIATI BACHTIAR ${ }^{1}$, \\ MUHAMAD SAHLAN ${ }^{2}$
}

${ }^{1}$ Department of Oral Biology, Faculty of Dentistry, Universitas Indonesia, Jakarta, Indonesia. ${ }^{2}$ Department of Chemical Engineering, Faculty of Engineering, Universitas Indonesia, Depok, Indonesia. Email: sriangky@ui.ac.id

Received: 21 April 2017, Revised and Accepted: 13 July 2017

\section{ABSTRACT}

Objective: The aim of this study is to analyze the amount of calcium and phosphate ion released by casein phosphopeptide-amorphous calcium phosphate (CPP-ACP), which supports the remineralization and the effectiveness of propolis wax in suppressing the mass formation of Streptococcus mutans biofilm on caries-free subjects and to observe if these two active components are effective when combined into one substance and placed inside sugar-free chewing gum.

Methods: Twenty-five samples of caries-free saliva before and after the mastication simulation (five concentrations of chewing gum) in vitro were observed to check for release of calcium and phosphate ions along with a biofilm assay. The release of calcium ions was detected using AAS, the release of phosphate ions was detected using spectrophotometry ultraviolet-visible, and the biofilm assay was detected using a crystal violet 96 -well plate ELISA and was evaluated with an ELISA reader.

Result: Chewing gum with a concentration of $0 \%$ prop $+5 \%$ CPP-ACP showed the highest release level of calcium ions (p<0.05) and phosphate ions ( $\mathrm{p}>0.05)$ and is significant in suppressing the mass formation of the $S$. mutans biofilm $(\mathrm{p}<0.05)$.

Conclusions: Mastication simulation of CPP-ACP-Propolis chewing gum can increase calcium and phosphate ion levels in caries-free saliva and decrease $S$. mutans biofilm mass formation; this can support remineralization and becomes a dental caries prevention alternative.

Keywords: Caries, Saliva, Casein phosphopeptide-amorphous calcium phosphate, Propolis wax, Biofilm.

(C) 2017 The Authors. Published by Innovare Academic Sciences Pvt Ltd. This is an open access article under the CC BY license (http://creativecommons. org/licenses/by/4. 0/) DOI: http://dx.doi.org/10.22159/ajpcr.2017.v10s5.23125

\section{INTRODUCTION}

Dental caries are still a major health problem in Indonesia. According to the Household Health Survey (SKRT) conducted by the Department of Health in 2001, in the category of complained and not complained about health problems, the prevalence of dental issues was the highest, with $60 \%$ of population complaining of a problem [1]. According to the Basic Health Research (Riskesdas) conducted by the Indonesian Ministry of Health in 2013, the prevalence of active dental caries is at $53.2 \%$, which increased from the previous survey in 2007 at $43.4 \%$ prevalence [2]. Dental health problems are on the top 10 most common health problems in Indonesia [3].

Dental caries are a pathological process that destroys dental hard tissues (enamel, dentin, and cementum) and are caused by multiple factors interacting (host, microorganism, substrate, and time) [4]. Streptococcus mutans produce acid from the fermentation of carbohydrates in food or drinks. The acid will influence the oral plaque's $\mathrm{pH}$ and initiate the demineralization process. The demineralization process dissolves hydroxyapatite (HA) components found in dental hard tissues. However, there is also a remineralization process that occurs when there are enough calcium and phosphate ions to reform the dissolved HA. Dental caries happen if demineralization is not balanced with remineralization [4].

To decrease and prevent cariogenic bacteria activity and suppress biofilm mass formation, especially $S$. mutans, there is a widely used natural antibacterial agent called propolis [5]. Propolis can inhibit bacteria colonization by destroying cell membrane and bacteria cytoplasm using active polyphenol substances called flavonoids [5]. Propolis must go through a refinement process before it can be used. The by-product from the refinement process is propolis wax, which contains polyphenol (2.4-5\%). The previous study has supported that propolis wax can inhibit $S$. mutans biofilm formation [6].

In dental caries prevention, besides using an antibacterial agent, remineralization should be promoted. Currently, there is a remineralization agent called casein phosphopeptide-amorphous calcium phosphate (CPP$\mathrm{ACP}$ ) that can be used in addition to fluoride in the non-invasive treatment of early lesion caries [7]. CPP-ACP can increase calcium and phosphate ions, thus promoting remineralization and preventing demineralization. Reynolds et al. supported that chewing gum with CPP-ACP promotes remineralization at rates $152 \%$ more than a control group [7].

An antibacterial agent and remineralization agent can work effectively if supported with a good oral environment, such as saliva. Saliva is a natural form of oral protection that contributes to the salivary flow rate, which can be increased with stimulation through taste and mastication, such as when chewing gum [8]. The purpose of this study was to analyze the amount of calcium and phosphate ions released by CPP-ACP, observe the effectiveness of propolis wax in suppressing the mass formation of S. mutans biofilm on caries-free subjects, and analyze if these two active components are effective when combined into one substance in sugarfree chewing gum.

\section{METHODS}

This experimental laboratory study was conducted at the Oral Biology Laboratory Faculty of Dentistry Universitas Indonesia and Chemistry 
Laboratory Faculty of Natural Sciences Institut Teknologi Bandung. The research protocol was approved by the Faculty of Dentistry Universitas Indonesia's Ethical Committee (Approval No. 74/Ethical Approval/ FKGUI/XII/2015). There were five groups using the sugar-free chewing gum containing $0 \%$ propolis wax $+0 \%$ CPP-ACP (negative control), $0 \%$ propolis wax $+5 \%$ CPP-ACP, $2 \%$ propolis wax $+5 \%$ CPP-ACP, $4 \%$ propolis wax $+5 \%$ CPP-ACP, and $6 \%$ propolis wax $+0 \%$ CPP-ACP. Each group consisted of five samples, so the total number of samples and subjects for the study was 25 .

The inclusion criteria for the saliva subjects were male or female, age 17-23 years old, good oral hygiene, a 0 DMFT score, good salivary rate $(1-2 \mathrm{ml} /$ minutes $)$, willing and cooperative, and willing to sign the informed consent. At the baseline, 25 subjects were instructed to brush their teeth and not consume food and drink for at least $3 \mathrm{hrs}$ before the sampling. The sampling was conducted around 10:00-11:30 a.m. Subjects were instructed to gargle, chew paraffin wax, and then collect $10 \mathrm{ml}$ saliva in a 15 -ml graduated test tube $( \pm 10-15$ minutes). The test results were referred to as the control saliva.

Mastication simulation was done through a pulverization process using a mortar and pestle for 25 saliva subjects using the CPP-ACP-Propolis chewing gum. The pulverization was conducted for 15 minutes with 1 collision/second. Movement variation and time were controlled. After this, the mastication saliva sample was collected in a 15 -ml graduated test tube. The saliva before and after mastication simulation was observed for the release of calcium and phosphate ions, along with any biofilm assay. The release of calcium ions was detected using atomic absorption spectroscopy (AAS) while phosphate ions were observed using an ultraviolet-visible spectrophotometer (spectrophotometer UVVIS); the biofilm assay was observed using a crystal violet 96-well plate ELISA and evaluated with an ELISA reader after $48 \mathrm{hrs}$ of incubation. Collected data were processed in a computer and analyzed using the SPSS software.

\section{RESULTS}

This study used 25 saliva samples from caries-free subjects. The saliva samples were used in a mastication simulation with CPP-ACP-Propolis chewing gum that had five different concentrations in vitro (each concentration had five samples). After mastication simulation, the release of calcium and phosphate ions, along with a S. mutans biofilm assay, was observed and compared to the results discovered before mastication simulation (saliva control). The result showed that there is a statistically significant change in the release of calcium ions in saliva before and after mastication simulation of CPP-ACP-Propolis chewing gum.

The concentration with the highest release of calcium ion was $0 \%$ propolis $+5 \%$ CPP-ACP and the lowest release was $0 \%$ propolis $+0 \%$ CPP-ACP (Fig. 1). The results showed that there was no statistically significant change in the release of phosphate ions in saliva before and after mastication simulation of CPP-ACP-Propolis chewing gum. The concentration with the highest release of phosphate ions was $0 \%$ propolis $+5 \%$ CPP-ACP and the lowest release was $4 \%$ propolis $+5 \%$ CPP-ACP (Fig. 2). The results also showed that there was a statistically significant change in $S$. mutans biofilm mass in saliva before and after mastication simulation of CPP-ACP-Propolis chewing gum after a 48-hr incubation period. The concentration with the largest decrease of S. mutans biofilm mass was $0 \%$ propolis $+5 \%$ CPP-ACP and the lowest was $4 \%$ propolis $+5 \%$ CPP-ACP. The $S$. mutans biofilm mass from chewing gum in all concentrations was lower than the propolis control (Fig. 3).

\section{DISCUSSION}

Since dental caries are a large health concern in Indonesia, alternative treatments to decrease dental caries are needed. This study used chewing gum with an active CPP-ACP and propolis wax, which can act as an antibacterial agent and promote remineralization. The study used

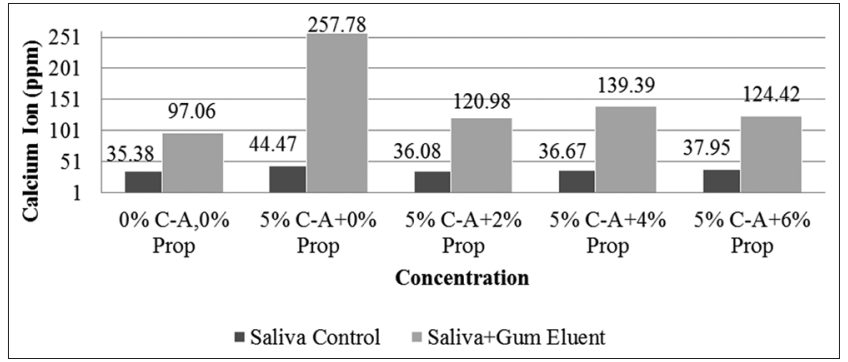

Fig. 1: Release of calcium ions in saliva before and after mastication simulation

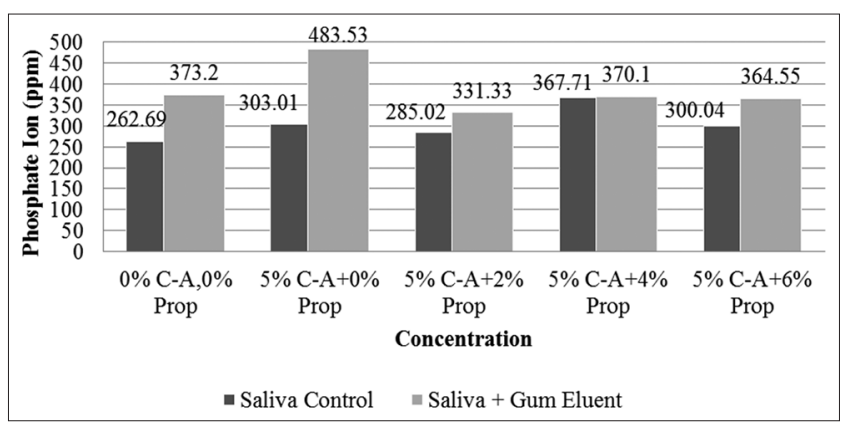

Fig. 2: Release of phosphate ions in saliva before and after mastication simulation

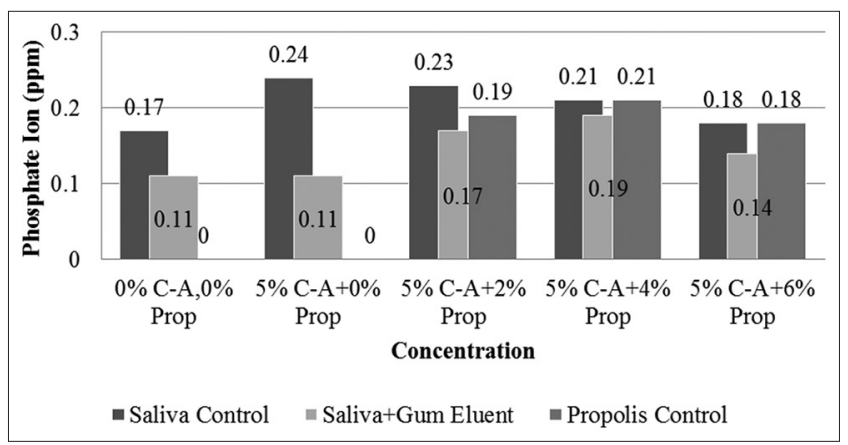

Fig. 3: Decrease of Streptococcus mutans biofilm mass in saliva before and after mastication simulation

various concentrations of propolis wax: $0 \%, 2 \%, 4 \%$, and $6 \%$ but the same concentration of CPP-ACP $5 \% \mathrm{w} / \mathrm{w}$, along with a negative control of $0 \%$ propolis wax and $0 \%$ CPP-ACP.

An increased release of calcium ions in saliva and gum eluent compared to a saliva control in all concentrations has been supported by various studies $[9,10]$. As the concentration of propolis wax increases, the release of calcium ions decreases. This might occur because of the contribution of the propolis wax agent in chewing gum that influences the release of ions from the CPP-ACP complex. Propolis wax is an oillike substance, whereas CPP-ACP is a water-like substances [11]. When they are combined, they can maintain separate roles inside the mouth. After mastication simulation, CPP-ACP and propolis wax split into ions (propolis wax consists of $77-87 \%$ wax), so there is a high chance that the wax covers ions from the CPP-ACP complex. As a result, when an analysis using AAS was performed, calcium ions might not have been detected. It can be concluded that as the concentration of propolis wax rises, the detected levels of calcium ions will drop.

Calcium ions are secreted with a saliva protein and are affected by the salivary flow rate [12]. Chewing gum can increase the salivary flow rate through mastication activity. It can be concluded that by chewing gum, the calcium ions in saliva increase [13]. 
A greater increase in the release of phosphate ions in saliva and gum eluent compared to the saliva control in all concentrations has been supported by various studies [9]. As the concentration of propolis wax increases, the release of phosphate ions decreases. The CPP-ACP complex releases phosphate ions, but with mastication simulation in this in vitro study, there was a chance that the phosphate ions would be split into phosphor (P) and oxygen $\left(\mathrm{O}_{2}\right)$. The saliva control and saliva and gum eluent were observed with UV-VIS spectrophotometry using a specific wavelength to detect phosphate ions at $700 \mathrm{~nm}$. It is possible that the split phosphor ions in the saliva may not have been detected by the devices used.

There is another possibility that emerges from calcium and phosphate ions' ability to form HA crystals, which can balance the demineralization and remineralization process. Calcium ions are more reactive than phosphate ions. In other studies, CPP has been shown to interact with calcium ions more than phosphate ions to form the CPP-ACP complex [14]. As a result, phosphate ions in CPP are lower and not as significant as calcium ions. The active agent flavonoid in propolis can inhibit calcium and phosphate ions forming in hydroxyapatite [15]. There is a chance that the combination of propolis wax and the CPPACP complex can inhibit each other's mechanisms.

This study showed that there $S$. mutans biofilm mass decreases in saliva and gum eluent when compared to the saliva or propolis control. This is the result of propolis wax, which is the residue from the extraction of pure propolis from the Trigona sp bee species. Propolis wax contains active polyphenol substances, called flavonoids, that act as effective antibacterial agents [16]. Another type of flavonoid in propolis, called apigenin, can inhibit the glucosyltransferase enzyme in bacteria, which plays a role in plaque formation [17]

Chewing gum creates a movement that induces salivary flow rate, helping to decrease the adhesion ability of $S$. mutans. Increasing the salivary flow rate can lead to increased oral $\mathrm{pH}$, buffer capacity, ability to clean food debris, and helpful ions that support the equilibrium between demineralization and remineralization [8]. In this case, the release of calcium and phosphate ions from CPP-ACP-Propolis chewing gum can lead to increased oral $\mathrm{pH}$.

The results of this study can be further explored by observing the release of calcium and phosphate ions in saliva and gum eluent in great detail. These ions can be influenced by many factors, such as the mechanism of mastication in vitro, calcium and phosphate ion levels in saliva, and calcium and phosphate ion levels in chewing gum.

\section{CONCLUSION}

Mastication simulation of CPP-ACP-Propolis chewing gum can increase calcium and phosphate ion levels in caries-free saliva and decrease S. mutans biofilm mass. The release of calcium and phosphate ions from the CPP-ACP complex is influenced by the concentration of the active agent, propolis wax, in chewing gum. Decreasing S. mutans biofilm is not directly proportional to increasing the propolis wax concentration in CPP-ACP-Propolis chewing gum. The effect of combining the two active agents of CPP-ACP and propolis wax into one chewing gum is not as effective as separating the two active agents.

\section{REFERENCES}

1. Soematri S, Supraptini S. Integrated survey for Indonesia sehat 2010. Bul Penelitian Kesehatan 2003;31(3):104-18.

2. Indonesian Ministry of Health. Basic Health Research 2013. Jakarta: Indonesian Ministry of Health; 2013.

3. Tjahja I, Sintawati FX. Factors affecting the oral hygiene of Jakarta citizens in 2007. J Ekol Kesehatan 2009;8(1):860-73.

4. Roberson TM. Studervant's Art and Science of Operative Dentistry. $4^{\text {th }}$ ed. St. Louis: The Mosby Inc.; 2002.

5. Duailibe SA, Gonçalves AG, Ahid FJ. Effect of a propolis extract on Streptococcus mutans counts in vivo. J Appl Oral Sci 2007;15(5):420-3.

6. Sharfina E. Formulasi Dan Uji Efektivitas Permen Karet Berbahan Aktif Lilin Propolis Untuk Pencegahan Karies Gigi. Thesis. Universitas Indonesia; 2014.

7. Reynolds EC. Casein phosphopeptide-amorphous calcium phosphate: The scientific evidence. Adv Dent Res 2009;21(1):25-9.

8. Mount G, Hum W. Preservation and Restoration of Tooth Structure. $2^{\text {nd }}$ ed. Australia: Knowledge Books and Software; 2005.

9. Cai F, Shen P, Morgan MV, Reynolds EC. Remineralization of enamel subsurface lesions in situ by sugar-free lozenges containing casein phosphopeptide-amorphous calcium phosphate. Aust Dent J 2003;48(4):240-3

10. Santhosh BP, Jethmalani P, Shashibhushan KK, Subba Reddy VV. Effect of casein phosphopeptide-amorphous calcium phosphate containing chewing gum on salivary concentration of calcium and phosphorus: An in-vivo study. J Indian Soc Pedod Prev Dent 2012;30(2):146-50.

11. Reynold EC. Dental mineralization. United States Pat 2014;2(12). Available from: http://www.europepmc.org/patents/PAT/US2008193557.

12. Kaur A, Kwatra KS, Kamboj P. Evaluation of non-microbial salivary caries activity parameters and salivary biochemical indicators in predicting dental caries. J Indian Soc Pedod Prev Dent 2012;30(3):212-7.

13. Keukenmeester RS, Slot DE, Putt MS, Van der Weijden GA. The effect of medicated, sugar-free chewing gum on plaque and clinical parameters of gingival inflammation: A systematic review. Int J Dent Hyg 2014;12(1):2-16.

14. Hegde MN, Moany A. Remineralization of enamel subsurface lesions with casein phosphopeptide-amorphous calcium phosphate: A quantitative energy dispersive X-ray analysis using scanning electron microscopy: An in vitro study. J Conserv Dent 2012;15(1):61-7.

15. Hidaka S, Okamoto Y, Ishiyama K, Hashimoto K. Inhibition of the formation of oral calcium phosphate precipitates: The possible effects of certain honeybee products. J Periodontal Res 2008;43(4):450-8.

16. Hudnall M. Composition containing fractionated bee propolis. United States Patent. No. 7.294.351; 2007. Available from: http://www.google. com/patents/US7294351.

17. Koo H, Hayacibara MF, Schobel BD, Cury JA, Rosalen PL, Park YK, et al. Inhibition of Streptococcus mutans biofilm accumulation and polysaccharide production by apigenin and tt-farnesol. J Antimicrob Chemother 2003;52(5):782-9. 